\title{
APROXIMACIÓN A UNA TEORÍA GENERAL DEL DERECHO JURISDICCIONAL Y SUS PRINCIPIOS GENERALES: CONCEPTO, TIPOS Y RÉGIMEN JURÍDICO. EL DERECHO FUNDAMENTAL AL ACCESO A LA JURISDICCIÓN O TUTELA JUDICIAL EFECTIVA
}

\author{
APPROACH TO A GENERAL THEORY OF JURISDICTIONAL LAW AND ITS GENERAL \\ PRINCIPLES: CONCEPT, TYPES AND LEGAL REGIME. THE FUNDAMENTAL RIGHT TO \\ ACCESS TO JURISDICTION OR EFFECTIVE JUDICIAL PROTECTION
}

Mónica Pucci Rey

Doctora en Derecho por la Universidad Complutense de Madrid. Profesora de Derecho Procesal en Eserp Business and Law School (Universidad Rey Juan Carlos) de Madrid (España) y en la Universidad Alfonso X el Sabio de Madrid (España).

ORCID: 0000-0002-8115-9501

E-mail: monicapuccirey@gmail.com

Convidada

\begin{abstract}
RESUMEN: Se formula la teoría general del Derecho Jurisdiccional como construcción doctrinal, por la que el conjunto de principios generales informadores del proceso lo transformarían desde un simple instrumento técnico a una categoría autónoma con significado transcendente de Justicia. De esta forma, tanto los principios jurídicos-naturales, de aplicación general a todo tipo de procesos, aunque con especialidades según se trate del proceso civil o del penal, como los principios técnicos, fruto de una elección del legislador, coadyuvan en su conjunto al fin último de la obtención de la Justicia por parte del justiciable. Para ello, estos principios y garantías procesales beben directamente de las fuentes de la Declaración Universal de Derechos Humanos, resto de normativa internacional aplicable y distintas constituciones nacionales. Mención especial merece el derecho fundamental al acceso a la jurisdicción o tutela judicial efectiva.
\end{abstract}

Palabras clave: Teoría general del Derecho Jurisdiccional. Principios generales. Principios jurídico-naturales. Principios técnicos. Derecho fundamental a la tutela judicial efectiva.

\begin{abstract}
The general theory of Jurisdictional Law is formulated as a doctrinal construction, whereby the set of general informative principles of the process would transform it from a simple technical instrument to an autonomous category with transcendent meaning of Justice. In this way, both the legal-natural principles, of general application to all types of processes, although with specialties depending on whether it is the civil or criminal process, as well as the technical principles, the result of an election of the legislator, contribute together to the ultimate goal of obtaining justice from the justiciable. To do this, these procedural principles and guarantees directly drink from the sources of the Universal Declaration of Human Rights, other applicable international regulations and different national constitutions. Special mention deserves the fundamental right to access to jurisdiction or effective judicial protection.
\end{abstract}

Keywords: General theory of Jurisdictional Law. General principles. Legal-natural principles. Technical principles. Fundamental right to effective judicial protection. 
SUMARIO: Introducción; 1.Naturaleza jurídica del proceso y su fundamento; 2.Tipos de proceso: concepción unitaria como base de la teoría general del Derecho Jurisdiccional; 3.Formas o sistemas del proceso penal: sistema acusatorio formal o mixto; 4.La teoría general del Derecho Jurisdiccional: tipos de principios generales; 5. Principios generales de la teoría general del Derecho Jurisdiccional: régimen jurídico del proceso civil; 5.1.Principios jurídico-naturales aplicables al proceso civil; 5.2.Principios técnicos aplicables al proceso civil; 6. Principios generales de la teoría general del Derecho Jurisdiccional: régimen jurídico del proceso penal; 6.1.Principios jurídico-naturales aplicables al proceso penal; 6.2.Principios técnicos aplicables al proceso penal; 7. Otros principios aplicables; 8 . El caso español: el derecho fundamental a la tutela judicial efectiva; 9. El caso español: derechos y garantías específicos del proceso penal; Conclusiones; Referencias.

\section{INTRODUCCIÓN}

Indiscutiblemente, en todo proceso deben regir una serie de principios y garantías procesales que, puestos al servicio de la Justicia, coadyuvan en su conjunto a la obtención de esta última por parte del justiciable.

Intención de este artículo es contribuir al nacimiento de una teoría general del Derecho Jurisdiccional, entendida como la base en que todo proceso debe ser construido, de forma que éste pasa de ser un simple instrumento técnico a tener un significado transcendente de Justicia (ANDRÉS IBAÑEZ, 2017, pp. 111-126).

Fundamento de esta construcción doctrinal es la propia naturaleza jurídica del proceso que explica los vínculos que unen a los sujetos que intervienen en el mismo (BRODERMANN FERRER, 2006, pp. 7-34).

Elaboraremos esta teoría general a partir del posicionamiento entre concepción dualista o unitaria del proceso, en sus dos vertientes o categorías de proceso civil y penal.

Abordaremos a continuación esta construcción jurídica a través del análisis de los principios generales que la conforman: principios jurídico-naturales, que informan cualquier tipo de proceso, y principios jurídico-técnicos o simplemente técnicos, que varían como consecuencia de una opción legislativa (GOLDSCHMIDT, 1925).

Mención y detenimiento especial merece el derecho fundamental al acceso jurisdiccional, o también conocido como derecho fundamental a la tutela judicial efectiva, tan ampliamente desarrollado por la doctrina jurisprudencial.

\section{NATURALEZA JURIDICA DEL PROCESO Y SU FUNDAMENTO}

Los vínculos que unen a los sujetos que intervienen en el proceso explican el fundamento y la propia naturaleza jurídica del mismo, incidiendo directamente en la clase de principios generales que en él se aplican, y por tanto, de igual manera en la construcción de la teoría general del Derecho Jurisdiccional.

Son múltiples las teorías que se han elaborado básicamente para explicar los vínculos que unen a los sujetos que intervienen en el proceso.

Podemos clasificar estas teorías en dos grupos: teorías de Derecho privado y teorías de Derecho público.

Las teorías de Derecho privado tienen su origen y se desarrollan en el Derecho Romano y son dos: la teoría que entiende el proceso como contrato de litis contestatio y la teoría del proceso como cuasi contrato de litis contestatio.

Sobre la primera podemos mencionar que en la época clásica del Derecho Romano se entendía que el proceso surgía de la voluntad concurrente del demandante y demandado. Esta voluntad concurrente era fuente de los poderes decisorios del juez y se manifestaba por parte del

Revista de Direito Brasileira | Florianópolis, SC | v. 24 | n. 9 | p.413-427 | Set./Dez. 2019 
demandante por el hecho de presentar la demanda y por parte del demandado por el hecho de contestarla.

En cuanto a la segunda, en la época postclásica el proceso se considera un cuasi contrato al entenderse que es suficiente la voluntad unilateral del demandante para que el juez adquiera su poder decisorio.

Estas teorías de Derecho privado han sido superadas por las teorías de Derecho público, entre otras razones, porque si bien en Roma el juez actuaba como un árbitro, tras una progresiva evolución, la función de juzgar la ha asumido el Estado.

Entre las muchas teorías de Derecho público que se han elaborado, cabe señalar la teoría de la relación jurídica, que se pronunció por primera vez por Von Bülow (VON BÜLOW, 1868), padre del Derecho Procesal como ciencia. Este autor entendió que los vínculos que unen a los sujetos del proceso no eran sino derechos y obligaciones recíprocos de carácter público.

Por otra parte, James Goldschmidt (GOLDSCHMIDT, 1929) consideró que en realidad los vínculos que unen a los sujetos del proceso no son derechos y obligaciones recíprocos, sino que se trata de meras situaciones jurídicas. Consideró además que en el proceso nunca cabe hablar de obligaciones, sino de cargas, es decir, de imperativos de propio interés.

La doctrina más moderna considera que el proceso no necesita para ser explicado utilizar categorías jurídicas de otras disciplinas, sino que el proceso es un concepto jurídico autónomo que tiene sus propios principios, régimen jurídico y fundamento, que no es otro que el de la realización de la Justicia (SILVA VALLEJO, pp. 14-35).

El proceso no es sólo un simple instrumento técnico, sino que de alguna manera tiene un significado transcendente de Justicia (FERRAJOLI, 2010), bien entendido, pues la Justicia que se pueda realizar en un proceso es limitada por factores diversísimos, entre otros la propia flexibilidad humana y para compensarla el propio Derecho Procesal regula ciertos medios. Los más claros serían los recursos y el llamado recurso de revisión contra sentencias firmes que ataca la cosa juzgada.

\section{TIPOS DE PROCESO: CONCEPCIÓN UNITARIA COMO BASE DE LA TEORIA GENERAL DEL DERECHO JURISDICCIONAL}

La posición dualista o unitaria del proceso tiene irremediablemente que ver con la construcción de la teoría general del Derecho Jurisdiccional, pues es básica para entender y decidir si los principios generales que la conforman son únicos y uniformes en todo tipo de proceso con simples variantes técnicas entre el proceso civil y el proceso penal, o al contrario, no puede existir una única construcción jurídica conjunta para ambos tipos de proceso.

En los orígenes no se distinguía entre el injusto civil y el injusto penal, de forma tal que el mismo instrumento servía para resolver cualquier tipo de conflicto.

Paulatinamente se fueron marcando cada vez más las diferencias y por ello cada vez más se fueron distinguiendo el proceso civil y el proceso penal.

Si el proceso civil y el proceso penal son dos categorías totalmente distintas, se trata de la posición dualista, y si hay una unidad fundamental en el concepto del proceso en la que hay dos especialidades será posición unitaria.

Quienes consideran que el proceso es un concepto único se basan en afirmar que los principios jurídico-naturales informan cualquier tipo de proceso y el hecho de que varíen los principios técnicos no es sino consecuencia de una opción legislativa.

En cambio, los partidarios del dualismo procesal consideran que en el proceso penal, particularmente en la fase de instrucción preliminar, no se cumplen ni el principio de imparcialidad, ni el de dualidad, ni el de igualdad, ni el de contradicción. Además, entienden que mientras en el proceso civil el demandante solicita la adjudicación de un derecho propio, en el proceso penal el acusador no tiene sino un simple derecho a ser parte del proceso, puesto que el derecho al castigo 
le corresponde exclusivamente al Estado, en virtud del ius puniendi. Afirman también que mientras en el proceso civil el procedimiento es lineal, en el proceso penal el procedimiento es escalonado.

Si la situación actual de la cuestión es admitir una tendencia uniformadora de los dos procesos hasta el punto de que existe un proyecto para hacer una ley procesal única, nuestra posición es claramente la unitaria, en la que se apoyaría la teoría general del Derecho Jurisdiccional, con una clara vocación integradora de ambos procesos con fundamento, como ya explicamos, en la transcendencia del mismo como realización de la Justicia (FERRAJOLI, 2010, pp. 141-174).

\section{FORMAS O SISTEMAS DEL PROCESO PENAL: SISTEMA ACUSATORIO FORMAL O MIXTO}

Antes de entrar a analizar los distintos principios generales que informan el proceso y por tanto conforman la teoría general del Derecho Jurisdiccional, es de vital importancia entender que si bien los principios básicos (jurídico-naturales) son de aplicación general a cualquier tipo de proceso, los mismos comportarán matices diversos a la hora de aplicarlos, según se trate del proceso civil o del proceso penal. De igual modo, los principios técnicos variarán en virtud de la opción legislativa elegida.

Estas diferencias de aplicación práctica del proceso penal respecto al civil en los principios jurídico-naturales, así como la diversidad de muchos principios técnicos de un tipo de proceso frente al otro, tienen que ser explicados y entendidos en base a la evolución histórica de ambos procesos (FERRAJOLI, 2016, pp. 1-10).

Si bien en los orígenes no se distinguía entre injusto civil y penal, de forma que ambos se solventaban a través del mismo tipo de instrumento, fueron surgiendo a lo largo de los siglos tres tipos históricos para el enjuiciamiento de delitos: el sistema acusatorio, el sistema inquisitivo y el sistema mixto o acusatorio formal.

El primero de ellos, el sistema acusatorio, tuvo vigencia en la Grecia Antigua y en la República Romana, y se caracterizaba por que la jurisdicción era ejercida por un jurado popular en única instancia y por tanto sin recurso; el ejercicio de la acción penal correspondía a cualquier ciudadano, siendo su ejercicio imprescindible para la iniciación del proceso; las partes procesales actuaban con plena igualdad de oportunidades; el encausado permanecía en libertad durante el transcurso del proceso; los medios de prueba tenían que ser siempre aportados por las partes, y para su valoración regía el principio de la libre convicción; el procedimiento era oral, público y contradictorio; la sentencia que se dictara producía efecto de cosa juzgada.

El segundo, el sistema inquisitivo, fue propio de la Roma Imperial, de la Baja Edad Media y fue desarrollado por el sistema canónico a través de la Inquisición. Se caracterizaba por que la jurisdicción era ejercida por magistrados permanentes que representaban al Rey o al Emperador, conforme a un sistema de doble instancia; la acción penal era ejercitada por el propio magistrado, que consecuentemente tenía atribuidas las funciones de instruir, acusar y juzgar; el sujeto encausado permanecía en prisión a lo largo de todo el proceso; las pruebas eran siempre acordadas de oficio y valoradas según un sistema de prueba tasada; el procedimiento era escrito, secreto y no contradictorio; la sentencia no producía efectos de cosa juzgada.

El último de los sistemas, el sistema mixto o también llamado sistema acusatorio formal, se instaura en Europa occidental a principios del siglo XIX como yuxtaposición de los dos anteriores. En él, la instrucción preliminar mantiene reminiscencias inquisitivas, mientras que el juicio oral es fundamentalmente acusatorio. Éste es el sistema imperante en la mayoría de los sistemas procesales penales actuales de los países occidentales. 


\section{LA TEORIA GENERAL DEL DERECHO JURISDICCIONAL: TIPOS DE PRINCIPIOS GENERALES}

La teoría general del Derecho Jurisdiccional trata de ser aquella construcción doctrinal que sirva de base informadora del cualquier tipo de proceso, para que el mismo sea conforme a la Declaración Universal de Derechos Humanos (ANDRÉS IBAÑEZ, 1999, pp. 289-316) y al resto de normativa internacional aplicable, es decir, a los tratados y acuerdos internacionales ratificados por cada país y que sobre derechos fundamentales y libertades a nivel constitucional se recogen y conforme a los que deben los mismos ser interpretados. Así expresamente se establece, en el caso de España, en el artículo 10.2 de su Constitución de 1978.

Los principios generales informadores del proceso pueden básicamente clasificarse en principios jurídico-naturales y principios técnicos. Estos últimos son consecuencia de una opción legislativa concreta.

Los principios jurídico-naturales son aplicables a todo tipo de proceso, civil y penal (y cualquier otro de cualquier jurisdicción distinta, es decir, contencioso-administrativo, social o laboral y militar), aunque con diversos matices de aplicación práctica, según se trate de uno u otro proceso. Básicamente, podemos hablar del principio de imparcialidad, del principio de independencia, del principio de dualidad, del principio de igualdad procesal y del principio de contradicción o audiencia.

Los principios técnicos en cambio son todos aquellos que son aplicables como consecuencia de una opción del legislador, que tendrá que elegir entre uno concreto o su contrario, según quiera imprimir en ese tipo de proceso unas connotaciones prácticas u otras. Son por tanto, estos principios técnicos, fundamentalmente herramientas o instrumentos procesales de opción legislativa. Podemos así, distinguir entre principio dispositivo o principio de oficialidad; impulso de oficio o de parte; principio de legalidad; principio de oralidad o escritura; principio de publicidad o secreto; principio de preclusión o elasticidad; principio de oportunidad o necesidad.

Estos principios básicos pueden ser complementados con otros como el principio de inmediación, de motivación de ciertas resoluciones judiciales, de la buena fe...

Todos estos principios generales son recogidos a lo largo de la legislación, o bien a nivel constitucional en forma de derechos fundamentales y libertades públicas, o bien a través de otras normas con rango legal (en el caso español, en la LOJP, la LEC, LECrim, básicamente).

\section{PRINCIPIOS GENERALES DE LA TEORIA GENERAL DEL DERECHO JURISDICCIONAL: RÉGIMEN JURIDICO DEL PROCESO CIVIL} técnico.

Los principios generales aplicables al proceso civil son de tipo jurídico-natural y de tipo

\subsection{PRINCIPIOS JURIDICO-NATURALES APLICABLES AL PROCESO CIVIL}

Los principios jurídico-naturales tienen que ser siempre respetados.

Vamos a analizar las especialidades de los mismos en el proceso civil.

En primer lugar, podemos hablar del principio de imparcialidad objetiva del órgano jurisdiccional (ANDRÉS IBÁÑEZ, 2009, pp. 41-72). Se trata de un principio básico que se predica del órgano jurisdiccional objetivo y neutral, de tal forma que si en él concurre alguna circunstancia que le impida ser objetivo en un caso concreto, debe abstenerse de conocer, y si no lo hace, las partes podrían recusarlo. Es una imparcialidad objetiva, no subjetiva, por lo que basta con que se dé alguna de estas causas para que deba abstenerse. 
En segundo lugar, podemos hablar del principio de independencia, que también se predica del órgano jurisdiccional. Significa que cada juez es autónomo a la hora de resolver las controversias. A diferencia de lo que ocurre con el Ministerio Fiscal, la organización piramidal del poder judicial no implica dependencia jerárquica.

En tercer lugar, el principio de dualidad supones reconocer en todo proceso la existencia de dos posiciones contrapuestas, al menos formalmente: la posición actora del demandante y la posición del demandado, aunque puede ocurrir que no sea un sujeto frente a otro, sino una pluralidad de sujetos activos frente a un solo demandado, es decir, un litisconsorcio activo. En cambio, si la pluralidad de sujetos se produce en la parte pasiva, estaríamos hablando de un litisconsorcio pasivo, mientras que si se da en ambas posiciones, sería un litisconsorcio mixto. En cuanto a que se trate de dos posiciones enfrentadas al menos formalmente, tener en cuenta que no siempre que se acude a un proceso ha habido un conflicto previo, como pueda ser en los procedimientos de mutuo acuerdo.

Como cuarto principio, debemos mencionar el principio de igualdad procesal, que se deriva del principio de igualdad ante la ley. Supone otorgar a las partes que intervienen en el proceso las mismas oportunidades. Hace referencia a una igualdad formal.

Como quinto principio, el de contradicción, que supone que los actos procesales son simétricos o correlativos, de forma que cada una de las partes pueda discutir y contra-argumentar lo esgrimido por la parte contraria. No confundir este principio con el principio de audiencia, que se suele expresar con el aforismo de que nadie puede ser condenado sin ser oído, aunque esta frase no es correcta, pues realmente el principio de audiencia viene a significar que nadie puede ser condenado sin haberle dado la oportunidad de ser oído. Tampoco se debe confundir el principio de contradicción con el principio de defensa, que significa que el juez debe dar a cada parte la posibilidad de utilizar todos aquellos instrumentos que la ley regula para el sostenimiento o mantenimiento de su respectiva posición, de forma que si no se cumple lo explicado se produciría indefensión, aunque para que ésta se produjera en realidad el resultado procesal tendría que haber sido distinto del que se hubiera producido de haber hecho pleno uso del derecho de defensa.

\subsection{PRINCIPIOS TÉCNICOS APLICABLES AL PROCESO CIVIL}

Los principios técnicos implican que el legislador tiene la opción y la posibilidad de elegir entre dotar al proceso de determinadas características o de sus contrarias, por lo que los principios técnicos elegidos suelen analizarse en contraposición a su opuesto.

En primer lugar, el legislador puede optar entre el principio dispositivo y el principio de oficialidad. Como regla general, el principio dispositivo rige en aquellos procesos en los que están en juego intereses privados, mientras que el principio de oficialidad rige en aquellos procesos en los que están en juego intereses públicos. Por tanto, el principio dispositivo informa al proceso civil y la oficialidad informa al proceso penal, aunque existen excepciones porque hay materias civiles que no son estrictamente privadas y materias penales que no son estrictamente públicas.

En el principio dispositivo las partes procesales tienen pleno dominio sobre sus derechos materiales y procesales, siendo libres de ejercerlos o no. De esta forma, el principio dispositivo tiene una múltiple manifestación.

Como primera manifestación, se deja a iniciativa de los particulares el comienzo o iniciación del propio proceso. A esta manifestación se le llama también principio de justicia rogada. En contraposición, en el principio de oficialidad, cuando se comete un hecho delictivo, quiera o no quiera el ofendido, el proceso se va a iniciar, como consecuencia del principio de necesidad.

Otra manifestación del principio dispositivo hace referencia a la delimitación del objeto del proceso, puesto que: este principio fundamenta la congruencia de la sentencia; de él depende la impugnación de las resoluciones judiciales, ya que recurrirla o no depende de si se pide; la ejecución de la sentencia también depende de si se pide; y por último, la carga de alegar y probar 
corresponde en exclusiva a las partes a través del principio de aportación de parte. En contraposición a lo explicado, en el principio de oficialidad todo lo anterior es independiente de la voluntad de las partes.

En segundo lugar, el legislador puede optar por establecer un impulso procesal de parte o un impulso procesal de oficio. El impulso procesal es aquella actividad según la cual un acto del procedimiento una vez concluido permite pasar al siguiente, es decir, es la actividad que sirve para hacer avanzar el procedimiento. Esta actividad puede encomendarse a las partes o al órgano jurisdiccional. En el sistema procesal español hasta 1924 el impulso procesal era de parte y desde entonces, y corroborado por la Ley Orgánica del Poder Judicial, el impulso en todos los procesos se hace de oficio.

En tercer lugar, el legislador puede optar entre el principio de preclusión o el de elasticidad. La preclusión implica que cada acto procesal tiene un plazo o momento concreto para poder ser realizado, pasado el cual ya no se puede realizar. En contrario, el principio de elasticidad significa dejar a las partes escoger el momento oportuno para la realización del acto. En nuestros sistemas procesales occidentales rige el primero de preclusión, pero atenuado por el principio de eventualidad o de acumulación eventual, que significa dar la oportunidad a las partes de presentar simultáneamente todas las alegaciones que les convengan aunque sean incompatibles entre sí, ante la eventualidad de que no tengan la oportunidad de hacerlo después.

En cuarto lugar, el legislador debe optar entre los principios de oralidad o de escritura, que hacen referencia a la forma de los actos. En nuestro Derecho, la oralidad predomina tanto en el proceso penal, como en el proceso civil. En este último como consecuencia en el Derecho Procesal español de la Ley de Enjuiciamiento Civil 1/2000, de 7 de enero, que introdujo este principio informador también en el proceso civil. Continuando con el Derecho español, el artículo 120.2 de la Constitución establece que el procedimiento será predominantemente oral, sobre todo en materia criminal. Significa elevar a rango constitucional un simple principio técnico. La oralidad lleva aparejada la concentración procesal y ésta a su vez la inmediación judicial, que exige al juez que esté presente durante la práctica de la prueba y todas aquellas diligencias orales determinantes del resultado del asunto.

En quinto y último lugar, el proceso puede ser público o secreto. La regla general es la publicidad, aunque se reconocen excepciones cuando así lo exija el orden público, la moral, el respeto al ofendido o a su familia.

\section{PRINCIPIOS GENERALES DE LA TEORIA GENERAL DEL DERECHO JURISDICCIONAL: RÉGIMEN JURIDICO DEL PROCESO PENAL}

Los principios generales aplicables al proceso penal son también de tipo jurídico-natural y de tipo técnico.

\subsection{PRINCIPIOS JURIDICO-NATURALES APLICABLES AL PROCESO PENAL}

Los principios jurídico-naturales son esenciales a todo proceso.

Sin embargo, en materia penal, los principios ya analizados en relación al proceso civil, tienen ciertas peculiaridades, que deben examinarse teniendo en cuenta el sistema procesal vigente en la mayoría de los países occidentales en la actualidad: el sistema acusatorio formal o mixto (prima el sistema inquisitivo en la fase de instrucción y el sistema acusatorio en la fase de juicio oral o de plenario).

En primer lugar, debemos decir que el principio de imparcialidad en materia penal tiene su principal manifestación en el principio del juez no prevenido, que significa que la instrucción preliminar y la fase de juicio oral tienen que estar encomendados a órganos jurisdiccionales diferentes. 
En segundo lugar, el principio de independencia no presenta peculiaridades en materia procesal penal. Significa que cada juez ejerce su función autónomamente, sin dependencia jerárquica.

En tercer lugar, el principio de dualidad, significa que con carácter general, en todo proceso deben existir dos posiciones diferentes. En materia penal, el principio de dualidad se tiene que cumplir siempre en la fase de juicio oral o de plenario, mientras que en la fase de instrucción puede ocurrir que exista parte acusadora y no exista parte acusada, o al revés.

En cuarto lugar, el principio de igualdad implica en general que ambas partes procesales han de tener las mismas oportunidades de actuar, conocido como igualdad de armas. Este principio de igualdad en el orden penal siempre rige en la fase de juicio oral, mientras que en la fase de instrucción preliminar puede darse la desigualdad entre las partes por dos razones fundamentales: porque el Ministerio Fiscal tenga como cometido la inspección directa del sumario o fase de instrucción, o porque el sumario o instrucción puede ser declarado secreto para todas las partes procesales, excepto para el Ministerio Fiscal.

En quinto lugar, el principio de audiencia, muy relacionado con los principios de contradicción (o principio contradictorio) y de defensa. Significa que nadie puede ser condenado sin haberle dado la oportunidad de ser oído. En el proceso penal rige, pero por un lado es obligatoria, salvo pequeñas excepciones, la presencia física del encausado en el juicio, es decir, salvo excepciones, no se admite la condena en rebeldía, y por otro lado, para el encausado la defensa es también obligatoria, en el sentido que si él no nombra abogado defensor, le será nombrado de oficio aunque tenga recursos económicos.

\subsection{PRINCIPIOS TÉCNICOS APLICABLES AL PROCESO PENAL}

En el proceso penal, las opciones elegidas por el legislador serían las expuestas a continuación.

En primer lugar, el principio de oficialidad, que es el reverso del principio dispositivo y que tiene las siguientes manifestaciones.

Respecto de la iniciación del proceso, cuando el delito cometido sea perseguible de oficio, la instrucción preliminar puede comenzar a iniciativa del propio juez.

Por otro lado, no son admitidos actos de disposición del ius puniendi que originen la terminación del proceso.

Respecto del tratamiento de los hechos y de las pruebas, se sigue el criterio de investigación oficial, que es el criterio opuesto al de aportación de parte. En cuanto a los hechos, el principio de investigación oficial rige en la fase de instrucción preliminar, pero no en la fase de juicio oral. En cuanto a las pruebas, tanto en la instrucción preliminar como en la fase de juicio, el órgano jurisdiccional podrá acordar la práctica de aquellas que estime oportunas, sin necesidad de petición de parte.

En cuanto a la congruencia de la sentencia, que en materia penal se denomina correlación entre acusación y sentencia, ésta no está fundamentada en el principio dispositivo, sino en el principio acusatorio que rige en la fase de juicio oral.

El segundo de los principios sería del de legalidad, que a su vez tiene dos manifestaciones: el principio de legalidad penal y el principio de legalidad procesal.

Respecto al principio de legalidad penal, éste conlleva que sólo son delitos o faltas (delitos leves) aquellos hechos tipificados como tales en el Código Penal.

Respecto al principio de legalidad procesal, significa que el proceso es la única estructura posible para la imposición de penas, que necesariamente el Ministerio Fiscal tendrá que ejercitar la acción penal cuando tenga conocimiento de la existencia de un hecho con apariencia delictiva, y que nadie puede ser juzgado sino en la forma señalada en la ley, pues se trata de una garantía procedimental. 
El tercer principio técnico aplicable al proceso penal sería el de oralidad, que rige en la fase de juicio oral, pero no en la fase de instrucción.

El cuarto principio es de publicidad, que rige en la fase de juicio oral, pero no siempre en la instrucción, que puede ser declarada secreta.

El quinto y último principio sería el de oportunidad, muy relacionado con el principio dispositivo. Es el criterio que rige con mayor o menor alcance en el proceso penal de los países anglosajones. Significa atribuir al Ministerio Fiscal el poder para disponer, bien con amplitud de criterio, o bien (según los países) bajo condiciones especificadas en la ley, la conveniencia de ejercitar o no la acción penal, e incluso la manera y alcance de ejercitarla. Éste es el principio que habilita al Ministerio Fiscal para poder transigir con la defensa las condiciones de la acusación. En España rigen hoy y con carácter general los principios contrarios, es decir, el de legalidad y oficialidad. Sin embargo, desde 1988 se está empezando a introducir, y ello a pesar de que el Código Civil prohíbe la transacción de la acción penal, y a que el artículo 124 de la Constitución Española establece el criterio de legalidad como criterio de intervención del Ministerio Fiscal.

\section{OTROS PRINCIPIOS APLICABLES}

Podríamos contemplar otros principios, que pueden resultar implícitos en alguno de los anteriores: principio de prueba libre o tasada en la valoración de la prueba; principio de motivación de las sentencias (art. 120.3 Constitución Española); principio de congruencia y exhaustividad de las sentencias; principio de mediación o inmediación en la relación entre el tribunal y el material fáctico; principios de concentración, preclusión y publicidad que producen aceleración del procedimiento (GIMENO SENDRA, 2017, pp. 45-64).

Incluso el listado de principios podría aumentarse: principio de unidad de jurisdicción, principio de la buena fe procesal, principio de proporcionalidad, principio de economía procesal..., rigiendo con mayor o menor fuerza en los distintos procesos (GIMENO SENDRA, 2015, pp. 23128).

\section{EL CASO ESPAÑOL: EL DERECHO FUNDAMENTAL A LA TUTELA JUDICIAL EFECTIVA}

Todo el conjunto de principios analizados hasta ahora y que puestos al servicio de la Justicia conforman la aquí llamada teoría general del Derecho Jurisdiccional, en el caso español, se concretan y recogen a través de las distintas fuentes del Derecho Procesal, que es fundamentalmente la ley, entendida como la legalidad de carácter superior (tratados internacionales y Constitución) y la legalidad estricta (LOPJ, LEC, LECrim).

Dentro de la legalidad de carácter superior, los tratados internacionales tienen importancia creciente como fuente del Derecho Procesal, debido a la cada vez mayor importancia de las relaciones internacionales.

En cuanto a la Constitución Española, recoge ésta determinados preceptos que tienen que ver con derechos fundamentales y libertades públicas y que por tanto vinculan a todos los poderes públicos, según el art. 53.1 CE, y además son susceptibles de ser protegidos y amparados, a petición de cualquier ciudadano, ante los tribunales ordinarios por un procedimiento basado en los principios de preferencia y sumariedad y, en su caso, a través del recurso de amparo ante el Tribunal Constitucional (TC), según el art. 53.2 CE.

Las normas constitucionales sobre derechos fundamentales (FERRAJOLI, 2006).en materia procesal serían el art. 17, que reconoce el derecho a la libertad personal, estableciéndose en él las condiciones y requisitos mínimos de la detención preventiva; el art. 18, que reconoce el derecho fundamental a la inviolabilidad del domicilio, recogiendo también los presupuestos mínimos para la entrada y registros domiciliarios; y por último y más importante en la materia que 
analizamos, el derecho fundamental a la tutela judicial efectiva del art. 24.1, junto a algunos derechos exclusivos del proceso penal (art. 24.2 CE).

En lo referente al derecho fundamental a la tutela judicial efectiva del art. 24.1 CE, la jurisprudencia del TC a lo largo de innumerables sentencias ha ido desgranándolo y dándole configuración en un contenido múltiple que podemos sistematizar en cuatro aspectos: el derecho de acceso a los órganos jurisdiccionales; el derecho al proceso; el derecho al debido proceso legal; y el derecho a la ejecución de las sentencias (SSTC 134/2008, 40/2014, 39/2015, 42/2017).

Vamos a analizar cada uno de esos contenidos del derecho fundamental a la tutela judicial efectiva, que fue entendido desde el principio por la jurisprudencia del TC como un derecho de configuración legal, cuya prestación se realiza a través de la actividad jurisdiccional (STC 99/1985).

El primero de esos contenidos o aspectos, el derecho de acceso a los órganos jurisdiccionales, supone la necesaria remoción, o al menos la interpretación restrictiva, de todos aquellos obstáculos que impidan el acceso efectivo, y por tanto, conlleva la necesaria interpretación antiformalista de los preceptos procesales. Hay que tener en cuenta que los sistemas violentos para la resolución de conflictos están prohibidos por el ordenamiento jurídico, y los sistemas autocompositivos y heterocompositivos distintos del proceso (acuerdo entre las partes), sólo son aplicables cuando los derechos son disponibles. Ante esa prohibición o limitación de los mecanismos para la resolución de las controversias, es lógico reconocer a todos los sujetos la posibilidad de acudir a los órganos jurisdiccionales.

El segundo aspecto sería el derecho al proceso, que unido al derecho de acceso a los órganos jurisdiccionales implica el derecho de todas las personas a obtener una sentencia sobre el fondo del asunto, siempre y cuando concurran los requisitos procesales requeridos para ello.

El tercer aspecto supone el reconocimiento del derecho al debido proceso legal, que significa que en la tramitación de todo proceso se respeten las garantías procesales que están incluidas en la propia Constitución Española. Estas garantías son: el derecho al juez ordinario predeterminado por la ley; el derecho a un proceso sin dilaciones indebidas; el derecho de defensa; el derecho a un proceso con todas las garantías; derecho a un proceso público; y otros derechos exclusivamente aplicables al proceso penal.

En cuanto al derecho al juez ordinario predeterminado por la ley, conviene analizar los términos que componen dicha expresión (ANDRÉS IBÁÑEZ, 2018, pp. 5-21).

Sobre el término juez, la jurisprudencia del TC lo considera sinónimo de órgano jurisdiccional competente, es decir, si un asunto es resuelto por un órgano jurisdiccional incompetente, se consideraría vulnerado este derecho fundamental. Junto a esto, en otras sentencias el TC ha considerado que este derecho al juez ordinario no puede excluir las normas administrativas que regulan la composición y la constitución de los órganos jurisdiccionales.

En lo referente al término ordinario, ha de mencionarse que ha de tratarse de un órgano ordinario, es decir, existe prohibición de creación de juzgados y tribunales ad hoc para casos concretos.

El término predeterminado, supone que el juez ordinario tiene que estar prefijado al caso, siendo dudoso si por caso hay que entender los hechos o el proceso en que se enjuician dichos hechos.

Por último, el término ley supone que la determinación del juez debe hacerse por ley orgánica u ordinaria. El artículo $81 \mathrm{CE}$ recoge que el desarrollo de los derechos fundamentales debe hacerse por ley orgánica y según el TC, por ley de desarrollo hay que entender exclusivamente aquella que hace efectivo un derecho fundamental, concluyendo el TC que no todos los derechos fundamentales están necesitados de un desarrollo en este sentido, y así ha considerado que las normas que regulan la jurisdicción y la competencia pueden ser leyes ordinarias, pero las normas que regulan la composición y constitución del órgano exigen ley orgánica, por establecerlo así expresamente la propia CE en su art. 122. 
En cuanto al derecho a un proceso sin dilaciones indebidas o derecho a que los procesos se resuelvan en un plazo razonable, estamos ante conceptos jurídicos indeterminados, cuyo contenido deberá ser precisado en cada caso concreto. El propio TC ha establecido una serie de criterios objetivos que habrán de tenerse en cuenta para determinar si en el caso concreto se ha vulnerado o no el derecho a un proceso sin dilaciones indebidas: un primer criterio objetivo, referido a la complejidad del propio proceso; un segundo criterio, sobre la conducta de las partes procesales; un tercer criterio, sobre la conducta de la propia autoridad judicial, lo que significa la comprobación en el caso concreto de si la dilación del proceso fue debida a una inactividad por parte del órgano jurisdiccional, pudiendo en tal caso, derivarse algún tipo de responsabilidad criminal; un cuarto criterio, analizando las consecuencias que la demora del proceso hubiera producido en las partes; y un quinto criterio, por el que se tendrá en cuenta el standard medio de la duración de procesos similares.

En cuanto al derecho de defensa, se reconoce por el art. $24 \mathrm{CE}$, desde el punto de vista positivo, pero también del negativo.

En sentido positivo, en cuanto que este derecho significa reconocer a las partes procesales el derecho a la asistencia letrada, el derecho a formular alegaciones, derecho a proponer medios de prueba pertinentes, y el derecho a recurrir las resoluciones. En definitiva, el derecho de defensa significa el derecho a utilizar todos aquellos instrumentos legales para el sostenimiento de cada posición procesal.

Por otro lado, el art. 24 reconoce también el derecho de defensa en sentido negativo, mediante la interdicción o prohibición de la indefensión, que se produciría cuando el juez impidiese a las partes procesales ejercitar su derecho de defensa en sentido positivo. Respecto de la indefensión, el TC ha venido a distinguir artificiosamente entre la indefensión procesal y la indefensión constitucionalmente relevante, cuando en realidad no hay más que una indefensión, que es la que se produce en el proceso. Otra cosa es que pueda considerarse indefensión cualquier infracción de cualquier norma procesal.

En cuanto al derecho a un proceso con todas las garantías, ha de entenderse por garantías todos los derechos y principios procesales que se encuentren reconocidos en los tratados internacionales, pero que no están formulados explícitamente en nuestra CE, como el principio de imparcialidad, el principio de audiencia y el principio de igualdad procesal, que no están recogidos en el art. $24 \mathrm{CE}$.

En cuanto al derecho a un proceso público, según el TC la publicidad de los procesos sólo puede ser limitada por causas legalmente establecidas, que serán interpretadas restrictivamente. Además, explica el TC que la limitación de la publicidad debe estar justificada en la protección de otro bien constitucionalmente relevante y además debe existir una proporcionalidad entre la medida prevista y la obtención del bien que se pretende garantizar.

En cuanto a otros derechos exclusivamente aplicables al proceso penal, debemos mencionar el derecho a no declarar contra sí mismo, derecho a no confesarse culpable, derecho a ser informado de la acusación, así como la presunción de inocencia.

Y por último, el cuarto aspecto se refiere al derecho a la ejecución de la sentencia, que según el TC implica el derecho a que la sentencia se cumpla en sus propios términos, lo cual supone que en principio el juez deberá adoptar todas las medidas que sean necesarias para ello.

\section{EL CASO ESPAÑOL: DERECHOS Y GARANTIAS ESPECIFICAS DEL PROCESO PENAL}

La Constitución Española (CE) establece una serie de derechos y garantías que son específicos del proceso penal, especialmente en el artículo 24.2 y que vamos a mencionar a continuación (FERRAJOLI, 2006, pp. 15-32). 
En primer lugar, el derecho al juez no prevenido, que ha de incluirse en el derecho a un proceso con todas las garantías (art. 24.2 CE).

En segundo lugar, el derecho y deber de la participación ciudadana a través del ejercicio de la acción popular y del jurado (art. $125 \mathrm{CE}$ ).

En tercer lugar, el derecho a ser informado de la acusación, si bien este derecho no puede interpretarse en un sentido estricto, ya que la acusación en sentido técnico se produce con la calificación provisional, y esta última se lleva a cabo cuando se abre la fase de juicio oral. Por eso, el TC ha dicho que el derecho a ser informado de la acusación ha de entenderse en sentido amplio, como derecho a ser informado de cualquier imputación que se realice (art. 24.2 CE).

En cuarto lugar, se recoge la prohibición de la tortura y de las penas o tratos inhumanos o degradantes en el art. $15 \mathrm{CE}$.

En quinto lugar, se reconoce el derecho a la libertad personal, sometiendo la detención a ciertos requisitos y condiciones (plazo máximo de 72 horas, derecho a nombrar abogado...), según los artículos 17.1 y $17.2 \mathrm{CE}$ ).

En sexto lugar, se regula la protección de la inviolabilidad del domicilio, en el que sólo se podrá entrar y registrar si concurre alguno de los presupuestos constitucionales (consentimiento del titular, resolución judicial o flagrancias) (art. 18.2 CE).

En séptimo lugar, también se reconoce la protección de la inviolabilidad de las comunicaciones, ya sean postales o telefónicas, salvo resolución judicial (art. 18.3 CE).

En octavo lugar, se recoge el derecho a no declarar contra sí mismo y a no confesarse culpable (art. 24.2).

En noveno lugar, la presunción de inocencia (art. 24.2 CE), que tiene según el TC dos manifestaciones: que ha de considerarse inocente a toda persona hasta que sea condenada por sentencia, y que la carga de la prueba de la culpabilidad recae sobre la acusación (SILVEIRA y NASPOLINI, 2018, pp. 858-875).

En décimo lugar, los principios de oralidad y publicidad (arts. 120.1 y $120.2 \mathrm{CE}$ ).

En decimoprimer lugar, el sometimiento del Ministerio Fiscal a los principios de legalidad e imparcialidad (art. $124 \mathrm{CE})$.

En decimosegundo lugar, se reconoce una policía judicial dependiente de los jueces y del Ministerio Fiscal (art. $126 \mathrm{CE}$ ).

Sin embargo, conviene no olvidar que también rigen otros principios no exclusivos del proceso penal (derecho al juez ordinario predeterminado por la ley, derecho a la tutela judicial efectiva...).

\section{CONCLUSIONES}

Existen una serie de principios y garantías procesales que rigen siempre en todo proceso de cualquier orden jurisdiccional y cuyo fin último es obtener la realización de la Justicia para el ciudadano.

Surge así la teoría general del Derecho Jurisdiccional, como construcción doctrinal, pero basada en la legislación y en la jurisprudencia, por la que todo ese conjunto de principios generales del Derecho Procesal supondrían la base de construcción del proceso, que pasaría de ser un simple instrumento técnico a tener un significado transcendente de Justicia.

Fundamento de esta teoría general del Derecho Jurisdiccional es la propia naturaleza jurídica del proceso y parte de la concepción unitaria del mismo, aunque con dos vertientes o categorías: proceso civil y proceso penal.

Como consecuencia de esa posición unitaria del proceso, podemos identificar un primer bloque de principios que afectan a cualquier tipo de proceso (los principios jurídico-naturales) y un segundo bloque, diferenciando entre los que afectan al proceso civil y los que afectan al proceso penal (los principios técnicos). 
Para entender esta última diferenciación entre proceso civil y penal, debemos recordar el actual sistema del proceso penal, el sistema acusatorio formal o mixto, como consecuencia de la unión o yuxtaposición del sistema inquisitivo, predominante en la fase de instrucción, con el sistema acusatorio, predominante en la fase de juicio oral.

Los principios generales que conforman la teoría general del Derecho Jurisdiccional tienden a informar los procesos conforme al mandato de la Declaración Universal de Derechos Humanos, resto de la normativa internacional aplicable y derechos fundamentales y libertades públicas constitucionales.

Así como los principios jurídico-naturales son de aplicación general a cualquier tipo de proceso, aunque con especialidades según se trate de uno u otro, los principios técnicos son consecuencia de una opción legislativa y por tanto se aplicará un principio o su contrario, según haya sido el deseo del legislador.

En el caso de España, el derecho fundamental a la tutela judicial efectiva ha sido ampliamente desarrollado por la jurisprudencia del Tribunal Constitucional (TC).

Aunque el análisis de principios es amplio, no se pretende sea un análisis exhaustivo, dada la naturaleza breve de este texto, y por tanto en ninguna manera se ha recogido un listado de principios con carácter de numerus clausus.

Se trata, al contrario, de una mera aproximación a los más importantes, que conformarían la teoría general del Derecho Jurisdiccional, aplicable a todos los ordenamientos jurídicos en su ámbito procesal y jurisdiccional, y cuyo objetivo no puede ser menos que la contribución a la realización y obtención de la Justicia por parte del justiciable.

\section{REFERENCIAS}

ALCALÁ-ZAMORA Y CASTILLO, N. (1947). "Proceso, Autocomposición y Autodefensa”.

ANDRÉS IBAÑEZ, P. (1999). "El juez nacional como garante de los derechos humanos", Consolidación de derechos y garantías: los grandes retos de los derechos humanos, pp. 289-316.

ANDRÉS IBAÑEZ, P. (2003). "Veinticinco años de administración de justicia y Constitución", Las sombras del sistema constitucional español. Coord por Juan Ramón Capella Hernández, pp. 151-174.

ANDRÉS IBAÑEZ, P. (2009). "Imparcialidad judicial e independencia judicial”, La imparcialidad judicial. Dir Carlos Gómez Martínez, pp. 41-72.

ANDRÉS IBAÑEZ, P. (2009). “¿Qué cultura constitucional de la jurisdicción?”, El juez y la cultura jurídica contemporánea. Coord Faustino Gutiérrez-Alviz y Conradi, Javier Martínez Lázaro, Vol. 3, pp. 299-317.

ANDRÉS IBAÑEZ, P. (2017). "Sobre la pobreza cultural de una práctica jurisdiccional sin teoría”, Derecho PUCP: Revista de la Facultad de Derecho, no 79, pp. 111-126.

ANDRÉS IBAÑEZ, P. (2018). "Preconstitución legal del juez: un principio en espera de rigurosa aplicación”, Jueces para la democracia, nº 91, pp. 5-21.

BRODERMANN FERRER, L.A. (2006). “Relación jurídica procesal”, Revista Alegatos, nº 62, México, pp. 7-34. 
CALAMANDREI, P. (1943). "Instituciones de Derecho Procesal Civil”.

CARNELUTTI, F. (1936-9). “Sistema de Derecho Procesal Civil”.

CARNELUTTI, F. (1941). "Instituciones del Proceso Civil”.

CHIOVENDA, G. (1903). "La acción en el sistema de los derechos".

CHIOVENDA, G. (1906). "Principios (instituciones) de Derecho Procesal Civil”.

ESPAÑA. Constitución Española de 1978.

ESPAÑA. Ley Enjuiciamiento Criminal. Real Decreto de 14 de septiembre de 1882.

ESPAÑA. Ley Orgánica del Poder Judicial. LO 6/1985, de 1 julio.

ESPAÑA. Ley Enjuiciamiento Civil.

ESPAÑA. STC 99/1985, de 30 septiembre.

ESPAÑA. STC 134/2008, de 23 octubre.

ESPAÑA. STC 40/2014, de 11 marzo.

ESPAÑA. STC 39/2015, de 2 marzo.

ESPAÑA. STC 42/2017, de 24 abril.

FERRAJOLI, L. (2006). “Las garantías constitucionales de los derechos fundamentales”, Doxa: Cuadernos de filosofía del derecho, $\mathrm{n}^{\circ} 29$, pp. 15-32.

FERRAJOLI, L. (2006). "Sobre los derechos fundamentales", Cuestiones constitucionales, Revista mexicana de derecho constitucional, $\mathrm{n}^{\circ} 15$.

FERRAJOLI, L. (2010). “Las fuentes de legitimidad de la jurisdicción”, Reforma judicial: Revista Mexicana de Justicia, no 15-16.

FERRAJOLI, L. (2010). "Per una teoria dei diritti fondamentali", Diritto pubblico, Vol. 16, n 12, pp. 141-174.

FERRAJOLI, L. (2016). “Jurisdicción y Ejecución Penal. La cárcel”, Crítica penal y poder: una publicación del Observatorio del Sistema Penal y los Derechos Humanos, no 11, pp. 1-10.

GIMENO SENDRA, V. (2015). "Introducción al Derecho Procesal”, Ediciones Jurídicas Castillo de Luna- UNED, pp. 23-128.

GIMENO SENDRA, V. (2017). "Derecho Procesal Civil”, Ediciones Jurídicas Castillo de LunaUNED, pp. 45-64. 
GOLDSCHMIDT, J. (1925). "Principios generales del proceso”.

GOLDSCHMIDT, J. (1929). “Derecho Procesal Civil”.

JIMÉNEZ LEUBE, J. (2016). "Fundamentos teóricos del debate constitucional: la "heterogénesis de los fines"”, Revista de Direito Brasileira, V. 15, n 6, pp. 83-93.

MÉNDEZ ROCASOLANO, M., MARIN GONZÁLEZ, L.A. (2018). “Perfiles axiológicos sobre la naturaleza normativa a propósito de la eficacia y la eficiencia en materiales fundamentales para la supervivencia. El caso de las normas voluntarias de gestión ambiental", Revista de Direito Brasileira, V. 19, nº 8, pp. 70-83.

PUCCI REY, M. (2019). "La Administración de Justicia ante el ciudadano: cuestiones y retos actuales", en Estado de Derecho, Políticas Públicas y Derechos Humanos, AA.VV., Coord Javier López de Goicoechea Zabala y Enrico Pascucci de Ponte, Thomson-Reuters Aranzadi, Fundación UAX, cap. 13, pp. 493-560.

SILVA VALLEJO, J.A. (). "Los fundamentos científicos del Derecho Procesal", Revista Themis, $\mathrm{n}^{\mathrm{o}} 14$, pp. 14-35.

SILVEIRA, V.O., NASPOLINI, S. (2018). “A presunçao de inocência como un direito humano fundamental na constituçao brasileira e sua aplicaçao pelo Supremo Tribunal Federal”, Revista Electrónica do Curso de Direito da UFSM, V. 13, nº 3, pp. 858-875.

VON BULÖW, O. (1868). "Excepciones y Presupuestos Procesales”. 